\title{
ANNE CARSON TRADUTORA DE ANTÍGONA: PERFORMANCE E TRADUÇÃO DE UM GRITO
}

\author{
Anne Carson translator of Antigone: performance and translation of a scream
}

\author{
Otávio Guimarães Tavares \\ (iD) https://orcid.org/0000-0002-1083-6448 \\ Universidade Federal do Pará, Belém, Instituto de Letras e Comunicação, PA, Brasil. \\ 66075-110-ilc.ufpa@gmail.com
}

\begin{abstract}
Resumo: Anne Carson é atualmente uma das mais aclamadas poetas, ensaístas, dramaturgas e tradutoras de língua inglesa, entretanto, a precisão destes termos se torna nebulosa diante da autora que tem como traço fundamental a mescla e desarticulação dos limites literários. Este procedimento marca Carson como alguém que pensa o literário a partir do ato tradutório, entendido por ela como a possibilidade de deixar duas realidades distintas visíveis, criando um ambíguo local que não pode existir, porém que é apresentado e performado a nossa frente. Dentro deste escopo, proponho olhar sua tradução da Antígona de Sófocles, titulada Antigonick, como um artefato de linguagem, uma partitura para realização de um ato de linguagem, para a realização do grito que chamamos de Antígona. Esta será pensada junto à tese de multiplicidade tradutória linguística presente em Borges, Cassin e Ricoeur, em que a tradução pode ser compreendida como um elogio ao múltiplo, como um saber se movimentar entre fronteiras e limites, um mover rumo a diferenças; fato que está presente na tentativa de Carson de traduzir algo distinto - o silêncio - de uma forma distinta - catástrofe -, de pensar outra possibilidade para aquela linguagem que fuja ao discursivo comum, dando voz a uma fúria contra o clichê e tendo como base a ololyga, grito ritual feminino da Grécia antiga, e as concepções da mulher como aquela que rompe limites por excelência, aquela que polui, que desloca e que toca com a voz. Por fim, a partir das concepções de Carson, argumento que a tradução e a performance são modos privilegiados para pensar o mundo, a multiplicidade e as diferenças.
\end{abstract}

Palavras-chave: Anne Carson. Antígona. Tradução. Performance. Corpo.

Abstract: Anne Carson is currently one of the foremost poet, essayist, dramatist, and translator in the English language, nevertheless, the precision of these terms becomes foggy when confronted with the author's process of merging and disarticulating literary limits. These procedures mark Carson as one who thinks the literary from the perspective of translation, understanding it as the possibility of allowing two distinct realities to be simultaneously visible, creating an ambiguous plane which cannot exist, yet is presented and performed before us. Within this view, I propose to analyze Carson's translation of Sophokles's Antigone, titled Antigonick, as a linguistic artifact, a score for performing a language act, for the realization of the scream we call Antigone. I shall base this on the idea of a translative multiplicity as read in Borges, Cassin, and Ricoeur, in which translation can be understood as a praise of multiplicity,

Esta obra está licenciada sob uma Creative Commons - Atribuição 4.0 
as a way of moving between boundaries, always heading towards differences. This is present in Carson's attempt to translate something distinct - silence - in a distinct manner - catastrophe -, of seeking another possibility for language that departs from everyday discursively, giving voice to a fury against cliché, and having as her paradigm the ololyga, an ancient Greek women's ritual scream, and the idea of women as the one who confounds boundaries, one who pollutes, who moves that which she touches with her voice. In all, based on Carson's conceptions, I argument that translation and performance are privileged modes for thinking the world, in its multiplicity, and its differences.

Keywords: Anne Carson. Antigone. Translation. Performance. Body.

\author{
"like poor Mrs. Ramsay \\ who died in a bracket \\ of To the Lighthouse" \\ Eurydike em Antigonick (2012) \\ "translation in itself is a performance" \\ Barbara Cassin (2018a)
}

\title{
Introdução
}

Anne Carson é uma das mais aclamadas poetas, ensaístas, dramaturgas e tradutoras de língua inglesa e é, ao mesmo tempo, uma reconhecida helenista e professora de grego antigo. Contudo, é necessário ter claro que a precisão destes termos se torna nebulosa diante de uma autora que, em grande parte, tem como traço fundamental de sua poética a mescla e desarticulação dos limites e fronteiras dos diversos gêneros, produzindo um constante tocar entre diferentes formas literárias, com narrativas em verso, poemas ensaísticos, e obras que fogem a definições precisas, aliadas a destra movimentação entre Sappho e Artaud, Woolf e Thucydides, Sófocles e Beckett. Não obstante, Carson não simplesmente abole as distâncias entre textualidades amorfas. Ela traça um jogo de explicitar a diferença entre distâncias, evidenciando seu contato em um grau profundo, ao mesmo tempo em que nubla as fronteiras. Ou, apropriando as palavras que Carson utiliza em uma reflexão sobre eros em seu livro Eros the Bittersweet, poderíamos dizer que ela intenta "To know both, keeping the difference visible" $\left(1998\right.$, p. 69) ${ }^{1}$. Este procedimento, de acordo com Jessica Fisher (2015), seria uma das bases da poética de Carson: "Her brilliance as a writer is to show us the simultaneous proximity and distance between things, and in this sense she is always a translator - that is, one who carries something across a distance" $(2015, \text { p. 12) })^{2}$. Mais do que um procedimento superficial de construção de gêneros e contato entre autores, trata-se de um modo de produzir textualidades que permearia toda a obra da autora, tendo como base paradigmática e metodológica o ato tradutório.

É a partir daí que devemos começar a pensar Carson: como uma tradutora que

\footnotetext{
1 "conhecer a ambos, mantendo a diferença visível" (todas as traduções em nota são de minha autoria).

2 "Seu brilho como escritora é que ela nos mostra, simultaneamente, a proximidade e distância entre as coisas, e neste sentido ela é sempre uma tradutora - isto é, alguém que carrega algo através de uma distância".
} 
compreende o ato tradutório como a possibilidade de deixar duas realidades visíveis; como o ato de criar um terceiro lugar que habita a indeterminação temporal do antigo e do agora, do atual e do potencial. ${ }^{3}$ E é justamente isto que se torna visível em sua Antigonick (2012), uma tradução da Antigona de Sófocles entranhada de anacronismos, elementos metatextuais e invenções inusitadas que deixam o leitor em constante estado de estranhamento.

O título Antigonick nos apresenta com algo singular, podendo se referir ao personagem adicional Nick que, calado, mede as coisas do começo ao fim da peça (permanece em cena mesmo depois que todos saem), e que é lembrado pela expressão "in the nick of time", ao mesmo tempo em que pode indicar certa proximidade sonora com antagonic, antagônica, antagonista. Esta imagem é levantada por Carson (2012) no prefácio intitulado "The Task of the Translator of Antigone". Trata-se de uma espécie de epístola/monólogo de Carson tradutora endereçado a Antigona, em que a autora revisita a obra, sua recepção, suas releituras e se questiona acerca do ato tradutório. Nela, Carson (2012, p. 3) diz: "dear Antigone: / your name in Greek means something like 'against birth' or 'instead of being born' / what is there instead of being born?". O antagonismo à vida e ao domínio de Creon ${ }^{4}$ estaria então na raiz linguística do nome e título da peça.

Em termos do texto, a tradução de Carson conta com quase uma ausência de pontuação, versos inconclusos, alterações entre uma sintaxe prosaica e uma sintaxe em staccato, mudanças bruscas de registros e uso de expressões populares contemporâneas. Comparada a outras conceituadas traduções de Antigona para o inglês, como a de Robert Fagles (SOPHOCLES, 1984) e a de F. Storr (SOPHOCLES, 1912), Carson (2012) encurta o tamanho dos versos e reduz drasticamente a extensão do texto, dando à peça uma dinâmica e velocidade com vigor e vida. ${ }^{5}$

Entre a diversidade de passagens anacrônicas, há, desde a referência à nova poderosa lancha de Creon, até a menção do coro à Antigona de Bertold Brecht (2003) - e o fato do diretor alemão fazer a atriz encenar a tragédia com uma porta amarrada nas costas - A peça começa com uma citação proferida por Antigona: "we begin in the dark / and birth is the death of us" (CARSON, 2012, p. 9, grifo da autora) ${ }^{6}$ e passa à discussão entre ela e Ismene acerca da autoria do trecho. Antigona o atribui a Hegel e Ismene a Samuel Beckett. ${ }^{7}$ Judith Butler (2012), ao resenhar a tradução de Carson (2012), nota que os anacronismos parecem estar:

$[\ldots]$ knitting the reception of Antigone into the play itself, letting us know that our only access to this play is through this present time, and yet showing that

\footnotetext{
${ }^{3}$ Gérard Genette (1997) nota a situação problemática de traduzir um texto antigo para uma língua contemporânea. Ato que, em seus piores extremos, pode cair na artificialidade de tentar emular a língua de uma época ou pode cair em uma atualização que descaracterize o texto.

${ }^{4}$ Com exceção de "Antígona", sigo a grafia de Carson para a transliteração dos nomes gregos.

${ }^{5} \mathrm{O}$ tamanho da peça se deve pragmaticamente à intenção inicial da autora de fazer uma história em quadrinhos e não uma peça teatral.

6 "nós começamos no escuro / e o nascer é nossa morte".

${ }^{7}$ A referência em questão é, de fato, uma variação do trecho inicial do Piece of Monologue, de Beckett (2010), "Birth was the death of him", fazendo uma alteração do passado da terceira pessoa para a primeira pessoa plural do presente.
} 
this time is still bound to that classical one (CARSON, 2012, n.p). ${ }^{8}$

Os anacronismos e referências contemporâneas são um modo dar forma e marcar a ambiguidade deste terceiro lugar tradutório.

Ao lado destes estão os elementos metatextuais. Creon, ao discutir com Haimon, assume o uso de pronomes "thou", "thee", "thyne", com ares shakespearianos. Haimon, a certa altura, diz que irá deixar uma lacuna no texto e Creon, ao entrar em cena pela primeira vez, anuncia seus verbos e substantivos para o dia: “here are Kreon's verbs for today / Adjudicate / Legislate / Scandalize / Capitalize / here are Kreon's nouns / Men / Reason / Treason / Death / Ship of State / Mine" (CARSON, 2012, p. 14) ao que o coro reclama "'mine' isn't a noun" e Creon retruca "it is if you capitalize it" (CARSON, 2012, p. 14). ${ }^{10}$

De forma mais intricada, podemos notar uma fusão entre anacronismo, referências intertextuais e metatextualidade quando Eurydike anuncia a si mesma e localiza o lugar de sua fala na peça:

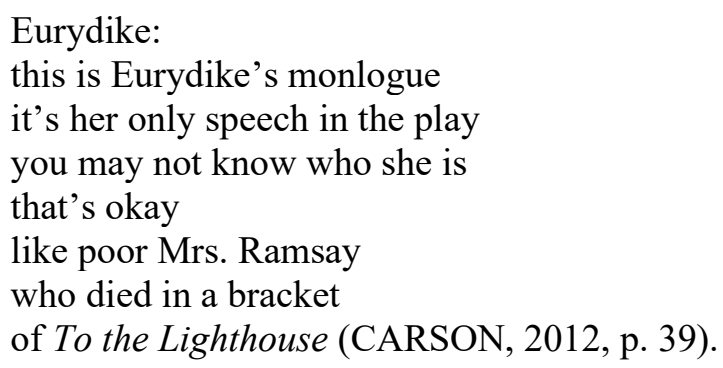

Ao sair de cena ela emula a autoridade da didascália ao dizer: "exit Eurydike bleeding from all orifices" 11 , só para ser confrontada pela didascália propriamente dita que diz: “[Eurydike does not exit]" (CARSON, 2012, p. 40), gerando uma espécie de confronto entre personagem e paratexto. Retomando a ideia inicial, podemos compreender que os anacronismos e metatextualidades - que devem ser compreendidos como interligados - estabelecem uma autoconsciência linguística da peça e constituem um traço fundamental para alcançar o terceiro lugar tradutório, enquanto mantem em evidência tanto o grego antigo quanto o presente.

Carson (2018), em entrevista a Will Aitken, menciona que ela tende a não pensar as peças a partir de personagens, e sim a partir da linguagem. ${ }^{12}$ A tradução de Antigonick teria surgido a partir de uma leitura da "Ode ao Homem" proferida pelo coro e se expandido a partir daí. Poderíamos então pensar a peça como um artefato de linguagem, uma partitura para realização um ato de linguagem, para a realização do grito que chamamos de Antigona. Antigonick estaria

\footnotetext{
8 "tecendo as recepções de Antigona na própria peça, deixando claro para nós que nosso único acesso a esta peça é a partir de nosso tempo presente, mas mostrando, também, que este tempo ainda está vinculado ao tempo clássico".

9 "aqui estão os verbos de Kreon para hoje / Adjudicar / Legislar / Escandalizar / Capitalizar / Maiusculizar / aqui estão os substantivos de Kreon / Homens / Razão / Traição / Morte / Navio do Estado / Meu".

10 "Coro: 'meu' não é um substantivo / Kreon: é se você o maiusculizar".

11 "sai Eurydike sangrando por todos os orifícios" "[Eurydike não sai]".

${ }^{12}$ A primeira edição de Antagonick, escrita a mão, marca essa continuidade de um só texto ao grafar todo o texto em maiúsculo em um continuo da escrita.
} 
então pensada como um objeto único, divergindo de uma visão mais tradicional de drama como diálogo de personagens. Fato que se torna mais claro diante de como a peça foi performada, visível tanto no Louisiana Literature Festival, em agosto de 2012, no Louisiana Museum of Modern Art, quanto no Moderna Museet, em Estocolmo, em 2015. Ambas consistiram em leituras públicas do texto por várias pessoas em relativo mono tom (tão caraterístico das leituras de Carson). O traço do texto como objeto único é fortalecido ainda pelo fato de que as didascálias são lidas ao público em uma espécie de não diferenciação entre texto e paratexto cênico. Este foco na linguagem é também a razão porque a autora indica, na mesma entrevista com Aitken, que as suas peças autorais seriam um desastre ${ }^{13}$ (CARSON, 2018). Não obstante, a peça compreendida como um bloco de linguagem é o que podemos notar na estrutura de uma de suas mais recentes produções, Norma Jeane Baker of Troy (2019), e que, de certa forma, lembra as peças de outra autora experimental anglófona, a matriarca da geração perdida de modernistas estadunidenses, Gertrude Stein. Em diversas peças de Stein não existe indicação do que é texto de fala, o que é didascália, quais são os personagens, deixando ao produtor o papel de destrinchar e performar aquela partitura textual. As indeterminações cênicas se tornam uma espécie de motor para múltiplas possibilidades de encenação.

\section{Ontologia do teatro e da tradução}

O teatro se dá no agir. Uma peça é uma obra que existe em evento e performance, recusando constantemente a estaticidade. Neste sentido, uma das características fundamentais de modo de ser do teatro como arte performática é que ele constantemente ressalta a diferença. Qualquer ator sabe que jamais encenará exatamente da mesma maneira o mesmo papel, mesmo que esta encenação ocorra noite após noite. Alguns até diriam que é neste tipo de atividade sequencial que se poderia notar a diferença intrínseca associada ao fazer performático. Este traço será mais profundo ainda se observarmos a história da encenação de uma mesma peça, digamos, o Hamlet de Shakespeare (2003), com seus traços, convenções e idiossincrasias ao longo dos tempos. Mesmo com pretensões de fidelidade, a encenação de uma peça será sempre outra com relação ao seu texto. Como nota Roman Ingarden (1973), ambos são objetos ontologicamente distintos. ${ }^{14}$

A tradução literária também compartilha deste modo de operar. Ela carrega o traço fundamental de efemeridade provisória, de modo que cada ato de traduzir engendra um novo artefato artístico com suas particularidades. Já há tempos, os estudos da tradução recusam qualquer noção de "fidelidade ao original" ou a ideia de que seria possível manter ou transferir alguma essência do texto de origem, tendo o "mesmo" objeto em outra língua. Em termos precisos, Paul Ricoeur (2012) fala em equivalência sem identidade na tradução. Segue que, próximo ao performático, a tradução é contextual, diversa e múltipla. Novamente, basta

\footnotetext{
${ }^{13}$ Tendo em vista o aparato conceitual de Carson, seria interessante indagar em que sentido há um desastre.

${ }^{14}$ Para uma análise mais aprofundada desta concepção acerca de uma diferença ontológica entre texto e encenação, sugiro a leitura do texto: "Do Teatro ao Digital: uma ontologia a partir de Roman Ingarden", de Otávio Tavares (2016).
} 
observarmos as diversas traduções de um mesmo texto literário para notarmos o grau de diferenças específicas entre traduções. Barbara Cassin (2018a) irá efetivamente dizer que: "translation in itself is a performance" $\left(2018\right.$, p. 4). ${ }^{15}$

O cenário fica mais interessante quando passamos à tradução teatral. Se a vida de uma peça teatral é sua constante apresentação, então esta, para viver, deve também mudar de língua. Ela deve ser traduzida para o máximo de idiomas possíveis para que possa ser encenada. A tradução, assim, estaria re-instanciando algo já feito para constante re-instanciação. Ambas trazem o distante (tempo, espaço, cultura) para o agora de quem interage. Ambas forçam um tocar e ser tocado por outro. Para performar Hamlet no Brasil necessito de uma tradução (que já será uma diferença com relação ao texto em inglês). E as performances irão ser sempre diferentes entre si. ${ }^{16}$ Portanto, a tradução teatral adiciona mais uma camada de diferença à tradução literária ao re-performar algo que é direcionado a uma constante re-performatização. Ambas indicam este eterno não-estável ou, como dirá Cassin (2018a), essa energia do uso da linguagem.

No caso específico da Antigona, Deborah H. Roberts (2010), em "Reading Antigone in Translation: Text, Paratext, Intertext”, faz um mapeamento da pluralidade tradutória textual no âmbito da interpretação e escolhas semânticas, apontando, por exemplos, múltiplas possiblidades do mesmo verso, ou diversos projetos tradutórios: tradução para aqueles que conhecem algo de grego antigo, tradução para performance, tradução didática, tradução para leigos etc. A isso, podemos também acrescer os outros modos de ver, pensar, dizer e agir Antigona em traduções que também operam algum nível de deslocamento espaciotemporal, isto é, em que o traduzir e performar se encontram profundamente entrelaçados para criação de outras Antigonas (dentro do ambíguo espectro de traduções e adaptações). Moira Fradinger (2010), em "Nomadic Antigone", prólogo do volume Feminist Readings of Antigone, elabora uma vertiginosa lista de diferentes Antigonas pós-1945 que incluem Antigonas caribenhas, Antigona em meio ao conflito das Irlandas traduzido em pés de canções populares, peças em que prisioneiros da apartheid encenam Antigona, Antigona nos pampas argentinos, Antigona em um asilo tentando executar o enterro de um pássaro, Antigona na Nigeria andando ao lado de Iemanjá, Antigonas e mais Antigonas. Mas, a pergunta que fica é: como entender tantas Antigonas no espaço tradutório teatral?

Terry Hale e Carole-Anne Upton (2014) notam que o teatro, com sua efemeridade e flexibilidade, acolhe perfeitamente tal diversidade. Poderíamos até dizer que esta ambiguidade entre traduzir e recriar é inerente ao modo de ser do teatro que, de acordo com Hale e Upton (2014), tende a uma relação de assimetria textual entre texto fonte e texto traduzido (ao invés de um simples texto paralelo). Mais do que isso, a própria força do teatro residiria justamente nessa impermanência, nesta constante abertura à reinvenção.

\footnotetext{
15 "tradução é em si mesma uma performance".

$16 \mathrm{O}$ caso de Hamlet é ainda mais interessante, pois o que normalmente aceitamos como o texto em inglês é normalmente um construto editorial do $1^{\circ}$ Fólio, $2^{\circ}$ Quarto e, sorrateiramente, o $1^{\circ}$ Quarto, não havendo, portanto, "um" texto plenamente "original" (O’SHEA, 2013).
} 
Não obstante, a pergunta que fica é: como podemos lidar com esta miríade de objetos? Jorge Luis Borges (2008), em seu texto "As Versões Homéricas", afirma a tradução como modos de ver o mesmo objeto:

O que são as varias versões da Ilíada, de Chapman a Magnien, senão diversas perspectivas de um fato móvel, senão um longo lance experimental de omissões e de ênfases? (Não há necessidade essencial de mudar de idioma, esse deliberado jogo da atenção não é impossível no interior de uma mesma literatura.) Pressupor que toda recombinação de elementos é obrigatoriamente inferior a seu original é pressupor que o rascunho $\mathrm{G}$ é obrigatoriamente inferior ao rascunho $\mathrm{H}$ - já que não pode haver senão rascunhos. $\mathrm{O}$ conceito de texto definitivo não corresponde senão a religião ou ao cansaço (BORGES, 2008, p. 103-104).

O argumento de Borges (2008) carrega certas proximidades com uma lição básica da fenomenologia acerca das coisas do mundo. Isto é, de que a identidade não é dada na coisa física. Apesar de certa integridade do objeto real, sempre apreendemos por facetas ou aspectos de uma coisa por vias experimentais provisórias. Nunca temos a coisa em-si completa e absoluta (SOKOLOWSKI, 1999). Trazendo esta noção para corporeidade perceptiva, Merleau-Ponty (2006) nota que é impossível ver e apreender uma coisa toda. Estamos sempre em um ponto de vista que vê parte do objeto e oculta outra. Estamos já sempre fundados em nossos corpos como ponto de vista base. Um objeto total - visto de todos os ângulos ou de ângulo algum - é uma projeção que não existe e nem pode existir, nem mesmo em nossa mente (pautada, como ela já sempre está, pela percepção).

Não obstante, o que na fenomenologia é uma constatação epistemológica com relação à construção de sentido, para Borges (2008) será base de uma elaboração sutil acerca da efemeridade como característica do modo de ser dos objetos:

O Quixote, graças a meu exercício congênito do espanhol, é um monumento uniforme, sem outras variações que as deparadas pelo editor, o encadernador e o tipógrafo; a Odisseia, graças a meu oportuno desconhecimento do grego, é uma biblioteca internacional de obras em prosa e verso, desde os versos de rimas emparelhadas de Chapman até a Authorized Version de Andrew Lang ou o drama clássico francês de Berard ou a saga vigorosa de Morris ou o irónico romance burguês de Samuel Butler (BORGES, 2008, p. 104-105).

Se há, portanto, uma existência múltipla provisória, nenhum texto literário é definitivo por si só. Não há uma condição de necessidade em sua versão "final” (o final é uma ficção, uma escolha contingente e sua valoração será sempre contextual/institucional). Há, em termos de uma recepção, uma espécie de galáxia em que o original (texto de partida) é um espaço vazio potencial diante das traduções. Ao mesmo tempo, Borges (2008) indica a constante valoração da construção desta galáxia - um elogio à multiplicidade -, que perpassa a dissociação do caráter negativo do trabalho tradutório, ao mesmo tempo em que o autor nota que estas implicações deveriam ser estendidas a todas as obras literárias, isto é, Borges (2008) indica o caráter contingente do literário e do tradutório e uma lição do segundo ao primeiro. 


\section{Multiplicidade linguística tradutória}

Em suas elaborações acerca da tradução, tanto Ricoeur (2012) quanto Cassin (2018a), partem da tese humboldtiana da pluralidade das línguas. Esta recusa à ideia de uma língua única ou universal (língua perfeita, língua originária) assume sempre já a pluralidade das línguas (e não um processo que vai do uno ao múltiplo). No caso específico de Cassin (2018a), esta tese é construída a partir das bases de uma diferença. Para a autora: "Language is nothing but the difference of languages. Language is tongues [...], and every tongue is linked with a worldview or, in other words, a culture" $(2018 \text {, p. } 2)^{17}$, ou mesmo: "Language is and is only the difference of languages" (CASSIN, 2009, p. 363) ${ }^{18}$. Não há, portanto, qualquer unidade abstrata como "linguagem", somente "línguas".

Este paradigma, ao modo de Borges (2008), desestabiliza qualquer universal seja ele da linguagem, da tradução ou do texto de origem. Ricoeur (2012) nota que esta noção de línguas implica na renúncia à ideia de uma tradução perfeita. Ela nos leva a viver, em suas palavras, com uma "deficiência aceita" (RICOEUR, 2012, p. 27). Carson (2001) irá dizer que o tradutor é aquele que tenta se meter entre um corpo e sua sombra, o corpo sólido e a sombra que cai e se movimenta pelo chão. Para Cassin (2018a), também dentro desta metáfora espaço-motor, a tradução pode ser definida como um "know-how with differences" (2018a, p. 1) ${ }^{19}$, uma capacidade de se movimentar a partir de um saber fazer com as diferenças, isto é, neste espaço de relações entremeio às diferentes línguas. E é a partir desta noção de tradução como fazer também empregada por Ricoeur (2012) -, e suas implicações como um agir, que devemos construir a ideia da tradução como performance.

Esta será a base do conceito de intraduzíveis de Cassin (2018): "Untranslatable is not what one does not translate but what one does not stop (not) translating" $\left(2018\right.$, p. 1) ${ }^{20}$. Está certo que esta noção surge perante o projeto do Dicionário dos Intraduzíveis (2018b), se referindo, sobretudo, a conceitos filosóficos ${ }^{21}$, mas trata-se de algo que podemos transpor, de certa forma, para os problemas com relação à língua grega e à vertiginosa quantidade de traduções de Antigona - da mesma maneira que Borges (2008) nota esta possibilidade com a obra de Homero -. Talvez algo mais, não só a língua, mas o que ela apresenta, o que se performa, também possam ser pensados como algo intraduzível que necessita de constante tradução, não parando nunca de ser traduzidos, trazido adiante como os dilemas do luto, da pólis, da família e da lei na sociedade helênica. A tradução, por sua não-identidade entre texto fonte e texto traduzido, e diante da diferença como base de toda língua, se constitui como um processo infinito, como constante fazer, como performance.

Fica claro, portanto, que a multiplicidade é ontologicamente inerente tanto ao ato

\footnotetext{
17 “Linguagem não é nada mais que a diferença de linguagens. Linguagem são línguas [...], e toda língua é ligada a uma visão de mundo ou, em outras palavras, uma cultura".

18 "A linguagem é e é somente a diferença de linguagens".

19 "um saber como com as diferenças".

20 "Intraduzível não é o que não se traduz, mas o que não se para de (não) traduzir".

${ }^{21}$ Para uma discussão precisa acerca do assunto, sugiro a leitura de: "Sobre a tradução de textos filosóficos", de Celso Braida (2019).
} 
tradutório quanto ao performático, derivados da própria linguagem como local da diferença. Além disto, há uma intercessão entre os modos de ser da tradução e do teatro que se mesclam no fazer tradutório teatral de modo a se tornarem íntimos em seu procedimento de recontextualização e recriação para um constante novo, fundado em elementos temporais, especiais e culturais. A diferença se torna então a base de operar destes dois devires entrelaçados. A tradução teatral talvez seja justamente o local para manter essa diferença aparente.

\section{Silêncio tradutório e fúria contra o clichê}

Em seu prefácio à Antigonick, Carson (2012) se pergunta acerca da tarefa da tradutora de Antigona e, a certa altura, diz:

Antigone, you do not,

any more than John Cage, aspire to a condition of silence you want us to listen to the sound of what happens when everything normal/musical/careful/conventional or pious is taken away (CARSON, 2012, p. 06). ${ }^{22}$

A referência ao compositor de 4'33' ' não é fortuita. Muito além do silencio, Cage intenta ouvir os sons que restam, os sons que vivem quando "tudo" é retirado. Para além da não correspondência semântica perfeita entre línguas, Carson (2008), em seu ensaio "Variations on the right to remain silent", argumenta que haveria um tipo de palavra que não tem a intenção de ser traduzível, "A word that stops itself” (CARSON, 2008, n.p). ${ }^{23}$

Ela usa como exemplo a erva Moly dada a Odisseu por Hermes para que este não seja subjugado pelo feitiço de Kirke. Trata-se do nome de uma planta na linguagem dos deuses, mas que não nos é dada no grego. Carson (2008) nos diz que é uma palavra que cai no silêncio, como se Homero houvesse jogado tinta branca sobre ela. De modo que, mesmo parecendo reconhecível, ao nos aproximarmos, nos deparamos com algo que não teríamos como reconhecer plenamente. Neste sentido, o silêncio, como algo não passível de um conteúdo semântico, se aproxima do grito desarticulado. Ambos apresentam um problema para a tradução.

Ao mesmo tempo, Carson (2008) entrelaça esta discussão a de um profundo desgosto pelo clichê. Ao explanar sobre a recusa de Joana D'Arc em dar contornos às "vozes" que a guiavam e o tortuoso percurso linguístico tradutório de seu depoimento entre francês médio e latim, Carson (2008) nos diz:

Joan wanted to convey the jar on the nerves without translating it into theological cliché. It is her rage against cliché that draws me to her. A genius is in her rage. We all feel this rage at some level, at some time. The genius

\footnotetext{
22 "Antígona, você, // tanto quanto John Cage, não aspira a uma condição de silêncio / você quer que a gente ouça o som do que acontece / quando tudo normal/ musical/ cuidadoso/ convencional ou piedoso é levado embora".

23 "Uma palavra que se detém".
} 
answer to it is catastrophe.

I say catastrophe is an answer because I believe cliché is a question. We resort to cliché because it's easier than trying to make up something new. Implicit in it is the question, Don't we already know what we think about this? Don't we have a formula we use for this? Can't I just send a standard greeting card or paste in a snapshot of what it was like rather than trying to come up with an original drawing? (CARSON, 2008, n.p). ${ }^{24}$

A tentativa de traduzir algo distinto - o silêncio - de uma forma distinta - catástrofe -, de pensar outra possibilidade para aquela linguagem que fuja ao discursivo comum e clichê, parece ser o que Carson (2008) entende como uma das tarefas da tradutora.

O clichê Antigona é também a normatividade na tradução de Antigona. Mesmo diante de inúmeras releituras da peça, Deborah H. Roberts (2010) nota, a partir da resenha de Howard Gaskill, a tendência (por acaso, por parte de tradutores homens) de que haveria um modo correto de traduzir a peça de Sófocles estabelecido por uma fortuna crítica interpretativa. Este "modo correto" - prescritivo - torna até mesmo "conhecer o grego" algo possível sem efetivamente conhecer o grego antigo (fato que Deborah Roberts (2010) infere pelo fato de que, ao indicar o original grego, Gaskill recorre à tradução de Robert Fagles). Há, portanto, uma espécie de Antigona normativa - um parâmetro geral - construída não por base de uma análise contextualizada da obra, mas a partir de recorrências interpretativas extratextuais, uma tradição de que tal verso deva significar tal coisa, uma tendência de apagar o silêncio e o realizar como clichê, mesmo diante de outras possibilidades tradutórias filologicamente válidas.

Carson se recusa a tomar escolhas que se mantenham de uma dada maneira somente devido à incorporação por uma tradição. Antigonick, uma tradução inventiva com seus anacronismos, metatextos e saídas inusitadas, seria a forma particular de Carson traduzir contra o clichê, em uma fúria contra o clichê, que abrange tanto as palavras que caem no silêncio, quanto a fuga daquilo que foi instituído nas traduções anteriores. Trata-se de traduzir Antigona como uma catástrofe.

O título do ensaio, "Variations on the right to remain silente" (2008), com sua apropriação da noção legal do direito ao silêncio para indivíduos detidos nos Estados Unidos, aponta para duas interpretações deste no âmbito literário: 1) o silencio como uma ação contra uma norma (contra uma exigência de sempre dizer algo, em que "dizer" implique um conteúdo semântico) e 2) o silêncio como a possibilidade de afirmar algo como "não traduzível" 25 , como não completamente apreensível em outra língua, tendo em vista que "Untranslatability is ilegal" (CARSON, 2008, n.p). Carson, portanto, nota o silêncio como direito, como ação positiva que

\footnotetext{
24 "Joana queria transmitir a perturbação sem traduzi-la em clichê teológico. É sua fúria contra o clichê que me atrai a ela. Um gênio está em sua fúria. Todos sentimos essa fúria em algum nível, em algum momento. A resposta genial a ela é a catástrofe.

Eu digo que a catástrofe é uma resposta porque acredito que o clichê é uma pergunta. Recorremos ao clichê porque é mais fácil do que tentar inventar algo novo. Está implícita a pergunta: Já não sabemos o que pensamos sobre isso? Não temos uma fórmula que usamos para isso? Não posso simplesmente enviar um cartão de postal padrão ou colar uma foto instantânea de como era, em vez de tentar fazer um desenho original?".

${ }^{25}$ Há aqui, como em Cassin (2018), uma estranheza no posicionamento em que "intraduzível" parece dizer não a não traduzibilidade, mas sim que existem nuanças impossíveis de serem carregadas "perfeitamente" para outra língua em uma tradução (ou seja, nega-se uma equivalência plena, mas não o ato de traduzir).
} 
afirma algo pela ausência.

Há algo aqui muito próximo a recusa à gramática e estilo que Samuel Beckett elabora em uma carta a Axel Kaun de 9 julho de 1937, e que acompanha a sua intenção "To drill one hole after another into it [language] until that which lurks behind, be it something or nothing, starts seeping through" (BECKETT, 2014, p. 518) ${ }^{26}$. Este trecho, transcrito por Carson (2012) no prefácio de Antigonick, ao lado da menção a Cage, marca a escolha por um modo de traduzir que, como o pintor Francis Bacon, mencionado em "Variations" (2008), pretende pintar o grito e não o horror, i.e., não a cena do grito, mas a sensação. Tentativa esta que é intuída por Judith Butler (2012) com relação à Antigonick ao dizer que "Her text becomes the verbal and visual scanning of a prolonged scream or cry" (2012, n.p) ${ }^{27}$. Carson (2012) marca sua intenção de traduzir não a descrição semântica do ato, mas o ato e sua energia, lembrando obviamente o caráter acional performático do teatro que não só mostra, mas torna presente.

É isso que surge ao falar da tradução que Hölderlin fez da Antigona:

What fascinates me is to see his catastrophe, at whatever level of consciousness he chose it, as a method extracted from translation, a method organized by the rage against cliché. After all what else is one's own language but a gigantic cacophonous cliché. Nothing has not been said before. The templates are set. Adam long ago named all the creatures. Reality is in chains (CARSON, 2008, n.p). ${ }^{28}$

Carson (2008) opta não só por uma tradução violenta, mas por uma tradução que violente uma tradição, uma língua e seu clichê. Daí podemos compreender as marcas livres de sua tradução; aqueles traços sem razão ou propósitos explícitos (notavelmente os anacronismos) que, como a própria autora afirma em entrevista a Will Aitken, surgem muitas vezes do tédio (CARSON, 2018). Este que pode ser entendido como aquilo que impele a algo novo, como aquilo que a move contra o clichê. Ao mesmo tempo, são atos de violência tradutória que tornam explícito a diferença entre passado e presente, marcando a tradução como este terceiro lugar. De modo parecido à indicação de Beckett (2010) no roteiro de Film - justamente um filme marcado pela violência entre precipere e percipi - que pretendia que duas visões fossem possível ao mesmo tempo, Carson (2008) marca com sangue esta incongruência existencial de sua tradução, mas a marca como possível. É aí que ela localiza o traduzir:

Most of us, given a choice between chaos and naming, between catastrophe and cliché, would choose naming. Most of us see this as a zero sum gameas if there were no third place to be: something without a name is commonly thought not to exist. And here is where we can discern the benevolence of translation. Translation is a practice, a strategy, or what Hölderlin calls "a salutary gymnastics of the mind," that does seem to give us a third place to be.

\footnotetext{
26 “fazer um buraco após o outro nela [linguagem] até que aquilo que habita por trás, seja algo ou nada, comece a vazar".

27 "Seu texto se torna uma escansão verbal e visual de um grito ou lamento prolongado".

28 “O que me fascina é ver sua catástrofe, em qualquer nível de consciência que ele tenha escolhido, como um método extraído da tradução, um método organizado pela fúria contra o clichê. Afinal, o que mais é a nossa própria língua, senão um gigantesco cacofônico clichê. Nada não foi dito antes. Os modelos estão definidos. Adão há muito tempo nomeou todas as criaturas. A realidade está acorrentada".
} 
In the presence of a word that stops itself, in that silence, one has the feeling that something has passed us and kept going, that some possibility has got free (CARSON, 2008, n.p). ${ }^{29}$

A tradução permite perceber o silêncio contra a monotonia do clichê. Mas pintar o grito não deve ser compreendido como ato puramente irracional. Seguindo os passos de Hölderlin, Carson (2008) aspira a um "high degree of self-consciousness that is present in their respective manipulations of catastrophe" (2008, n.p) ${ }^{30} 31$. Ela jamais se abstém ao minucioso cuidado filológico com o grego antigo e, a despeito do que os anacronismos possam aparentemente indicar, não projeta o tempo atual sobre a Grécia antiga (como tendem a fazer diversas adaptações). Como tradutora, Carson contextualiza a obra em sua época efetiva, almejando dar a ver o que esta pode nos dizer no agora (sem atemporalidades ou ahistoricismos simplórios).

\section{Fronteiras, vozes e poluição tradutória}

Mas então, qual o grito de Antigona, qual o grito da tradutora de Antigona quando tudo "normal/musical/careful/conventional or pious" é retirado? O que é essa voz que leva maravilhosamente à catástrofe? A resposta talvez possa ser traçada em paralelo à ololyga, grito ritual, grito feminino, grito coletivo, marca de uma performatividade coletiva de mulheres que estabelece uma união de vozes, corpos e afetos em consonância, que toca todos aqueles que escutam, para além da apreensão e controle do logos ou sophrosyne (auto-controle) racional masculino.

Em seu ensaio "The Gender of Sound", Carson (1995) descreve a ololyga como um grito agudo e perfurante proferido no momento climático de rituais (como no instante em que a vítima de um sacrifício é degolada), em eventos climáticos da vida real (como o nascimento de uma criança) e festividades femininas. Trata-se de um som fora de limites, um som que nenhum homem poderia produzir. Para estes, ser exposto a tal voz é estar politicamente nu, é confrontar aquilo que não pode ser limitado ou contido. Visto que a civilização é para os gregos uma função de fronteiras e limites, a ololyga representa um risco para a própria pólis, necessitando, como indica Carson (2000) em seu ensaio "Dirt and Desire: Essay on the phenomenology of

\footnotetext{
29 “A maioria de nós, dada a escolha entre o caos e nomear, entre a catástrofe e o clichê, escolheria nomear. A maioria de nós vê isso como um jogo de soma zero - como se não houvesse um terceiro lugar para estar: algo sem um nome é comumente pensado como não existindo. E aqui é onde podemos discernir a benevolência da tradução. A tradução é uma prática, uma estratégia, ou o que Hölderlin chama de "uma salutar ginástica da mente", que parece nos dar um terceiro lugar para estar. Na presença de uma palavra que se detém, nesse silêncio, tem-se a sensação de que algo nos passou e seguiu, que alguma possibilidade se libertou".

30 "Alto grau de autoconsciência que está presente em suas respectivas manipulações da catástrofe".

${ }^{31}$ Carson é notória por fundamentar suas escolhas tradutórias em um scholary muito bem construído, ao mesmo tempo em que utiliza anacronismos, intertextos, metalinguagens, entre tantos outros recursos. Joshua Wilkinson (2015) nota que esta aparente contradição está no cerne da obra de Carson: aderir fortemente ao texto, mas empregar uma série de anacronismos e "invenções" de cunho experimental. Isto que a autora expressa ao final de "Variations" quando diz que foi "trained to strive for exactness and to believe that rigorous knowledge of the world without any residue is possible for us" (CARSON, 2008, n.p), ao mesmo tempo em que fala na possibilidade do silêncio intencional das palavras e na tradução para criar catástrofes como algo que muito lhe agrada. "treinada para se esforçar pela exatidão e para acreditar que um conhecimento rigoroso do mundo sem nenhum resíduo é possível para nós".
}

Anu. Lit., Florianópolis, v. 25, n. 2, p. 119-138, 2020. ISSNe 2175-7917 
female pollution in antiquity", ser contida em momentos e locais específicos.

Carson (2000) observa que os Gregos antigos eram atentos a transgressões de fronteiras (boudaries). Em uma perspectiva em que o corpo humano pode ser visto como paralelo ao corpo político do estado, devemos ter em mente que o contato é uma forma de crise, seja ele físico, social, moral, emocional ou imaginário. Carson (2000) nota que o contato é transgressão: "The difficulty presented by any instance of contact is that of violating a fixed boundary, transgressing a closed category where one does not belong" (2000, p. 130). ${ }^{32}$ Dentro deste campo conceitual: "Dirt is a matter that has crossed a boundary I ought not to have crossed. Dirt confounds categories and mixes up form" (CARSON, 2000, p. 143). ${ }^{33}$

O problema das fronteiras pode ser compreendido como um problema de limitação corpóreo, sobretudo um problema de voz, pois é a voz que transita das entranhas do ventre e toca todos que a escutam. É ela que escapa às fronteiras na forma da ololyga. Ela força um tocar. E a mulher é este ser de fronteiras por excelência:

Woman is that creature who puts the inside on the outside. By projections and leakages of all kinds - somatic, vocal, emotional, sexual - females expose or expend what should be kept in. Females blurt out a direct translation of what should be formulated indirectly (CARSON, 1995, p. 129). ${ }^{34}$

Este confronto fica claro quando Carson (1995) nos diz que:

The masculine virtue of sophrosyne or self-control aims to obstruct this continuity, to dissociate the outside surface of a man from what is going on inside him. Man breaks continuity by interposing logos - whose most important censor is the rational articulation sound (CARSON, 1995, p. 129130). ${ }^{35}$

Daí podemos pensar tanto no ato de Antígona - não só de enterrar o corpo, mas como nota Butler (2000), de redobrar o ato ao declará-lo diante da pólis, diante de um espaço de qual ela não deveria poder participar - e o ato de Carson ao elaborar uma obra/tradução grito, uma catástrofe que força o toque, ao encontro de fronteiras. Se a mulher é vista não só como poluída, mas como uma poluível/poluída/poluente que coloca a sociedade em constante perigo de corrupção e contágio, podemos compreender Antigonick como uma Antigona poluída por outras temporalidades, por outros gritos que rompem os limites do texto. A ideia de um artefato linguístico único, apresentado por Carson como seu modo de pensar suas peças, pode ser compreendido como uma dissolução de fronteiras que cria uma continuidade textual vocálica,

\footnotetext{
32 "A dificuldade apresentada por qualquer instância de contato é a de violar uma fronteira fixada, transgredir uma categoria fechada à qual não se pertence".

33 “A sujeira é uma matéria que cruzou uma fronteira que não deveria ter cruzado. A sujeira confunde categorias e mistura formas".

34 “A mulher é aquela criatura que coloca de dentro para fora. Por meio de projeções e vazamentos de todos os tipos - somáticos, vocais, emocionais, sexuais - mulheres expõem ou gastam o que deveria ser mentido dentro. Mulheres cospem uma tradução direta do que deveria ser formulado indiretamente".

35 "A virtude masculina de sofrósine ou autocontrole visa obstruir essa continuidade, visa dissociar a superfície externa de um homem do que está acontecendo dentro dele. O homem quebra a continuidade interpondo o logos - cujo censor mais importante é a articulação racional do som".
} 
um enorme grito que, em seu caráter líquido de confabular e infringir fronteiras, é moldado, mas também altera, transforma e deforma aquilo que toca.

Esta associação à poluição e sujeira está linguisticamente marcada em Antigonick, no campo semântico utilizado por Creon ao caracterizar Antigona. Segundo Carson (2015), Creon e Antigona se opõem na própria morfologia de sua linguagem, no modo como pensam e falam. Não obstante, Antigona rompe fronteiras e as mistura, perturbando qualquer tentativa masculina de ordem. De acordo com Butler (2000), a medida que a peça caminha, Antigona "absorbs the very language of the [male] state against which she rebels, and hers becomes a politics not of oppositional purity but of the scandalously impure" (BUTLER, 2000, p. 5). ${ }^{36}$ Há em suas ações uma apropriação e subversão das estruturas básicas que fundamentam a sociedade grega. Ao se apropriar da voz e linguagem da lei para desafiar a lei, Antigona subverte e torna ambíguo os papeis de gênero. Ao mesmo tempo, é pela linguagem que Creon é afetado por Antigona. Carson (2018) nota que nas últimas cenas o discurso de Creon está completamente poroso e feminizado, participando da imagética líquida da linguagem. Ele foi moldado pela voz e linguagem de Antigona.

O ato de infringir fronteiras, este levar ao toque é uma estranha violência. Aitken (2018) nota que as imagens não violentas femininas são recebidas de forma extremamente violenta pelos homens. Creon sente constantemente castrado e feminizado por Antigona que apenas quer enterrar o irmão. Quem é tocado sente suas fronteiras e limites rompidos, mesmo que seja por uma não violência. Como nota Butler (2019) o poder do estado afirma a não violência como violenta para poder contrapô-la com violência. O que interessa aqui é pensar a tradução como esse lugar do toque, e levar ao toque, que funciona como uma estranha violência de um lugar impossível.

Se Cassin (2018a) afirma a tradução como um mover-se em meio à diferença, Carson (1995), a partir da ololyga, marca essa movimentação entre a diferença como um lugar corpóreo. A voz, o dizer, é, de acordo com Merleau-Ponty (2006), uma ação motor corpórea e o corpo é justamente esse lugar ambíguo entre eu e as coisas do mundo que sempre habito. $\mathrm{O}$ corpo é a ambiguidade máxima, este terceiro lugar entre pessoa e coisa, para usar uma noção de Esposito (2016). Neste sentido, ele também é a origem da vulnerabilidade. Butler (2006) bem nota esse lugar do corpo:

The body implies mortality, vulnerability, agency: the skin and the flesh expose us to the gaze of others, but also to touch, and to violence, and bodies put us at risk of becoming the agency and instrument of all these as well. Although we struggle for rights over our own bodies, the very bodies for which we struggle are not quite ever only our own. The body has its invariably public dimension. Constituted as a social phenomenon in the public sphere, my body is and is not mine. Given over from the start to the world of others, it bears their imprint, is formed within the crucible of social life (BUTLER,

\footnotetext{
36 “Absorve a própria linguagem do estado [masculino] contra o qual ela se rebela, e a dela se torna uma política não de pureza oposicional, mas do escandalosamente impuro".
} 


$$
\text { 2006, p. 26). }{ }^{37}
$$

Traduzir se torna então também um lugar corpóreo, um lugar marcado por esse contato de entranhas, esta crise entre tocar e ser tocado, como suas inevitáveis dimensões éticas.

Olga Castro (2017), teórica da tradução feminista, nota que devemos ter claro que a objetividade e neutralidade na tradução não passam de falácias. Neste sentido, as lições da ololyga e de Antigona são também da voz:

Every sound we make is a bit of autobiography. It has a totally private interior yet its trajectory is public. A piece of inside projected to the outside. The censorship of such projections is a task of patriarchal culture that (as we have seen) divides humanity into two species: those who can censor themselves and those who cannot (CARSON, 1995, p. 130). ${ }^{38}$

A tradução de Carson (2012) pode ser entendida como uma voz que marca seu gênero de forma complexa dentro do lugar da mulher grega e de uma Antigona a vociferar seu (estranho) lugar na pólis. ${ }^{39}$

De modo sutil e genial, Carson emula esse modo de ser de Antigona e o transforma em uma base metodológica para sua tradução, isto é, o método tradutório de Carson é profundamente implicado por aquilo que ela traduz. Ela lança mão de um scholary preciso para criar algo contra os clichês tradutórios. Ao modo de Antigona, ela incorpora a lei contra a lei, contra uma normatividade clichê da tradução. ${ }^{40}$ Como uma tradutora de teatro, ela produz o grito, cria uma partitura para uma catástrofe. Retomando novamente o comentário de Butler

\footnotetext{
37 "O corpo implica mortalidade, vulnerabilidade, agência: a pele e a carne nos expõem ao olhar dos outros, mas também ao toque e à violência, e corpos nos colocam em risco de nos tornarmos agência e instrumento de tudo isso também. Embora lutemos por direitos sobre nossos próprios corpos, os próprios corpos pelos quais lutamos nem sempre são apenas nossos. O corpo tem sua dimensão invariavelmente pública. Constituído como fenômeno social na esfera pública, meu corpo é e não é meu. Entregue desde o início ao mundo dos outros, ele carrega a marca deles, é formado no cadinho da vida social".

38 "Cada som que fazemos é um pouco de autobiografia. Possui um interior totalmente privado, mas sua trajetória é pública. Um pedaço de dentro projetado para fora. A censura de tais projeções é uma tarefa da cultura patriarcal que (como vimos) divide a humanidade em duas espécies: aqueles que podem se autocensurar e aqueles que não podem".

${ }^{39}$ Carson (2018) ressalta a ambiguidade e circularidade deste lugar: "There's nothing more conventional than a female burying her kinsman's body, although Kreon has, exceptionally outlawed this for the moment. Antigone has to oppose him by insisting on her own conventional function, has to force herself back into the female stereotype. But, being Antigone, she does so in a way that undermines the stereotype and draws attention to the undermining. This is perhaps why she buries the body twice, why she orders Ismene, 'proclaim it to all! I insist!' In order to mourn but also remain autonomous, she has to mourn to excess. But to mourn to excess is already a female stereotype. It all circles back into itself. She really can't escape - the equations are set. This seems to me effectively tragic in a larger way than the usual gender debates about this play allow" (CARSON, 2018, p. 120). "Não há nada mais convencional do que uma mulher enterrando o corpo de seu parente, embora Creon o tenha proibido excepcionalmente naquele momento. Antígona precisa se opor a ele insistindo em sua própria função convencional, precisa se forçar de volta ao estereótipo feminino. Mas, sendo Antígona, ela o faz de uma forma que subverte o estereótipo e chama a atenção para a subversão. Talvez seja por isso que ela enterre o corpo duas vezes e ordena a Ismene, 'proclame a todos! Eu insisto!' Para fazer o luto e ao mesmo tempo permanecer autônoma, ela tem que performar o luto em excesso. Mas luto em excesso já é um estereótipo feminino. Tudo retorna a si mesmo. Ela realmente não pode escapar - as equações estão definidas. Isso me parece efetivamente trágico de uma maneira maior do que os habituais debates sobre gênero acerca da peça permitem".

${ }^{40} \mathrm{O}$ campo semântico de alguns juízos tradicionais acerca da tradução é fortemente misógino, marcado por ideias de nacionalismo e adultério na figura da traição. É o caso clássico de "tradutor traidor" e "belas infiéis".
} 
(2012), a tradução de Carson (2012) se torna a escansão de um grito prolongado, grito que é entregue a nós para performar.

\section{Considerações finais}

Barbara Cassin (2009), ao falar do Elogio de Helena de Górgias (2005), menciona que o texto não só efetua uma persuasão, mas é uma performance epidíctica que produz um efeito mundo. A partir deste ato, habitamos um mundo em que uma Helena inocente é pensável e plausível. Há qualquer coisa de teatral nesta ação, pois o teatro nos apresenta realidades possíveis com energia e força, como carne e agir. Ele nos mostra as possibilidade, nos faz sentilas em nossas vidas. Neste sentido, Antigonick pode ser lida como uma partitura para pensar/dizer/agir Antigona, uma partitura para um grito.

Com Carson, traduzir é um modo de ser, pensar, perceber, agir e viver. Trata-se de um modo de estar entre mundos, explicitando a diferença entre distâncias, propondo um contato entre momentos. É um modo de ser e compor que permite habitar um terceiro lugar indeterminado de fronteiras. Trata-se de um modo de habitar e agir essa voz - essa ololyga -, de tocar e ser tocada.

Cassin (2018a), baseado no "plus d'une langue" de Jacques Derrida (2007) acerca da desconstrução, elabora uma noção de pluralidade existencial a partir da pluralidade linguística e tradutória:

More than one! More than one way of being a man, more than one language, more than one meaning, more than one translation and more than one good translation. Every translation - as any translator knows - engages you with more than one possibility (CASSIN, 2018a, p. 7). ${ }^{41}$

Esta multiplicidade tradutória, elogiada também por Borges (2008), deve ser a base para pensar o mundo, um modo de ser sempre distinto em sua diversidade, um modo de se movimentar na diferença sem apagá-la. É a partir dela que devemos pensar a tentativa de Carson (2012) de traduzir e retraduzir o que permanece em silêncio, de traduzir para catástrofe, de pensar outra possibilidade para fora do clichê, de entender as línguas como não dadas, como possibilidades ainda abertas para uma movimentação nos espaços fronteiriços. Torna-se, portanto, plausível pautar a tradução e o performático como lugar privilegiado para repensarmos os modos de ser humano em sua diferença constitutiva.

No final do seu ensaio "The Gender of Sound" Carson (1995) se pergunta:

I wonder if there might not be another idea of human order than repression, another notion of human virtue than self-control, another kind of human self than one based on dissociation of inside and outside. Or indeed, another

\footnotetext{
41 "Mais de um! Mais do que uma maneira de ser homem, mais do que uma língua, mais do que um significado, mais do que uma tradução e mais do que uma boa tradução. Toda tradução - como qualquer tradutor sabe - te confronta com mais do que uma possibilidade".
} 
A pergunta acerca de outros modos do humano, tendo em vista, sobretudo, uma questão de gênero, deve ser lida em paralelo ao clichê como pergunta de qual devemos procurar a resposta catástrofe. Traduzir Antigona é produzir um caminho possível. Antigonick é uma possibilidade de resposta que marca o ato tradutório como o de falar e deixar falar, como um tocar, deixar tocar e ser tocado. Ler e performar Antigonick é habitar e mover-se pela pluralidade de vozes, é habitar o espaço da diferença sem anular um ou outro, é desmanchar fronteiras e limites. A tarefa que pretende a tradutora de Antigona, Anne Carson (2012), talvez aparente simples, mas é de suma importância. Afinal, como diz Carson (2012):

dear Antigone,

I take it as the task of the translator

to forbid that you should ever lose your screams (CARSON, 2012, p. 6). ${ }^{43}$

E para nós que lemos esta tradução, que possamos aprender a performar os gritos como de Antigona e Carson.

\section{Agradecimentos}

Gostaria de agradecer a Rafael Brunhara, Jovelina Ramos, Celso Braida, Gilles Abes, Beatriz Regina Guimarães Barboza e Walter Costa. Este texto é de certa forma fruto de nossas conversas.

\section{Referências}

AITKEN, Will. Antigone undone: Juliette Binoche, Anne Carson, Ivo Van Hove, and the art of resistance. Saskatchewan: University of Regina Press, 2018.

BECKETT, Samuel. The Selected works of Samuel Beckett. New York: Grove Press, 2010. v. 3.

BECKETT, Samuel. The Letters of Samuel Beckett. Edição de Martha Dow Fehsenfeld e Lois More Overbeck. London: Cambridge University Press, 2014. v. 1.

BORGES, Jorge Luis. As versões homéricas. In: BORGES, Jorge Luis. Discussão. Trad. de Josely Vianna Baptista. São Paulo: Companhia das Letras, 2008, p.103-110.

BRAIDA, Celso. Sobre a tradução de textos filosóficos. In: CESCO, Andréa; ABES, Gilles; BERGMANN, Juliana (Orgs.). Teoria e prática da tradução: legendagem, HQ, textos técnicos e científicos. São Paulo: Rafael Copetti Editor, 2019, p. 143168.

BRECHT, Bertold. Collected plays: eight. Trad. de David Constantine. Edição de Tom Kuhn e David Constantine). London: Bloomsbury, 2003. v.8.

\footnotetext{
42 "Eu me pergunto se não haveria outra ideia de ordem humana que não a repressão, outra noção de virtude humana que não o autocontrole, outro tipo de "eu" humano que aquele baseado na dissociação entre o dentro e o fora. Ou, na verdade, outra essência humana que não o "eu"'.

43 "cara Antígona, / eu tomo como tarefa da tradutora / impedir que você algum dia perca seus gritos".
} 
BUTLER, Judith. Can't stop screaming. Public books, 5 set. 2012. Disponível em: www.publicbooks.rg/fiction/cant-stop-screaming. Acesso em: 12 abr. 2020.

BUTLER, Judith. Antigone's Claim: kinship between life and death. New York: Columbia University Press, 2000.

BUTLER, Judith. Precarious life: the power of mourning and violence. London: Verso Books, 2006.

BUTLER, Judith. The Force of non-violence: an ethico-political bind. London: Verso Books, 2019.

CARSON, Anne. The task of the translator of Antigone. In: SOPHOKLES. Antigonick. Trad. de Anne Carson. New York: New Directions Book, 2012, p. 3-6

CARSON, Anne. Eros the Bittersweet. Champaign: Dalkey Archive Press, 1998.

CARSON, Anne. A Handful of dirt (entrevista). In: AITKEN, Will. Antigone undone: Juliette Binoche, Anne Carson, Ivo Van Hove, and the art of resistence. Saskatchewan: University of Regina Press, 2018, p. 77-126.

CARSON, Anne. Norma Jeane Baker of Troy. London: Oberon Books, 2019.

CARSON, Anne. Variations on the right to remain silent. A Public space, New York, n. 7, 2008.

CARSON, Anne. The Gender of sound. In: CARSON, Anne. Glass, irony \& wine. New York: New Directions Book s, 1995, p. 119-142.

CARSON, Anne. Dirt and desire: essay on the phenomenology of female pollution in antiquity. In: CARSON, Anne. Men in the off hours. New York: Vintage/Random House, 2000, p. 130157.

CARSON, Anne. A note from the translator. In: SOPHOKLES. Antigone. Trad. de Anne Carson. London: Oberon Books, 2015, p. 5-8.

CARSON, Anne. Translator's foreword: screaming in translation. In: SOPHOCLES. Electra. Trad. de Anne Carson. Oxford: Oxford University Press, 2001, p. 41-48.

CASSIN, Barbara. Translation as politics. Javnost - The Public Journal of the European Institute for Communication and Culture, 9 fev. 2018a. Disponível em: https://doi.org/10.1080/13183222.2018.1418800. Acesso em: 2 jan. 2019.

CASSIN, Barbara. Sophistics, rhetorics, and performance; or, how to really do things with words. (Trad. de Andrew Goffey). Philosophy \& Rhetoric, v. 42, n. 4, p. 349-372, 2009. Disponível em: http://www.jstor.org/stable/25655365. Acesso em: 2 jan. 2019.

CASSIN, Barbara. (Coord.). SANTORO, Fernando; BUARQUE, Luisa (Org.). Dicionário dos Intraduzíveis. Belo Horizonte: Autêntica, 2018b. v. 1.

CASTRO, Olga. (Re)examinando horizontes nos estudos feministas de tradução: em direção a uma terceira onda?. Trad. de Beatriz Regina Guimarães Barboza. TradTerm, São Paulo, v. 29, p. 216-250, jul. 2017. 
DERRIDA, Jacques. Learning to live finally: the last interview. Trad. de Pascale-Anne Brault e Michael Naas. New York: Palgrave, 2007.

ESPOSITO, Roberto. As Pessoas e as coisas. Trad. de Andrea Santurbano e Patrícia Peterle. São Paulo: Rafael Copetti Editor, 2016.

FISHER, Jessica. Anne Carson's stereoscopic poetics. In: WILKINSON, Joshua Marie (Ed.). Anne Carson: Ecstatic lyre. Michigan: University of Michigan Press, 2015, p. 10-16.

FRADINGER, Moira. Nomadic Antigone. In: SÖDERBÄCK, Fanny (Ed.). Feminist readings of Antigone. New York: State University of New York Press, 2010, p. 15-23.

GENETTE, Gérard. Palimpsest: literature in the second degree. Trad. de Channa Newman, Claude Doubinsky. Nebraska: University of Nebraska Press, 1997.

GÓRGIAS. Elogio a Helena. In: CASSIN, Barbara. O Efeito sofístico: sofística, filosofia, retórica, literatura. Trad. de Paulo Pinheiro. São Paulo: Editora 34, 2005, p. 293-302.

HALE, Terry; UPTON, Carole-Anne. Introduction. In: UPTON, Carole-Anne (Ed.). Moving Target: Theatre Translation and Cultural Relocation. New York: Routledge, 2014, p. 1-13.

INGARDEN, Roman. The Literary work of art. Trad. de George Grabowicz. Evanston: Northwestern University, 1973.

MERLEAU-PONTY, Maurice. Fenomenologia da percepção. Trad. de Carlos Alberto Moura. São Paulo: Martins Fontes, 2006.

O'SHEA, José Roberto. Introdução. In: SHAKESPEARE, William. O Primeiro Hamlet inquarto de 1603. Trad. de José Roberto O’Shea. São Paulo: Hedra, 2013, p. 9-40.

RICOEUR, Paul. Sobre a tradução. Trad. de Patrícia Lavelle. Belo Horizonte: Editora UFMG, 2012.

ROBERTS, Deborah H. Reading Antigone in translation: text, paratext, intertext. In: WILMER, S. E.; ZUKAUSKAITE, Audrone (Eds.). Interrogating Antigone in postmodern philosophy and criticism. Oxford: Oxford University Press, 2010, p. 283-312.

SHAKESPEARE, William. Hamlet, Prince of Denmark. The New Cambridge Shakespeare. Edição de Philip Edwards. Cambridge: Cambridge University Press, 2003.

SOKOLOWSKI, Robert. Introduction to phenomenology. New York: Cambridge University, 1999.

SOPHOKLES. Antigonick. Trad. de Anne Carson. New York: New Directions Books, 2012.

SOPHOCLES. The Three Theban plays: Antigone, Oedipus the King, Oedipus at Colonus. Trad. de Robert Fagles. New York: Penguin, 1984.

SOPHOCLES. Sophocles: Oedipus the King, Oedipus at Colonus, Antigone. Trad. de F. Storr. London: Loeb, 1912. 
TAVARES, Otávio. Do Teatro ao digital: uma ontologia a partir de Roman Ingarden. Texto Digital, Florianópolis, Santa Catarina, Brasil, v. 12, n. 2, p. 35-58, jul./dez. 2016.

WILKINSON, Joshua Marie. Introduction. In: WILKINSON, Joshua Marie (Ed.). Anne Carson: Ecstatic lyre. Michigan: University of Michigan Press, 2015, p. 1-9.

\section{NOTAS DE AUTORIA}

Otávio Guimarães Tavares (nonada1@gmail.com) é professor no Instituto de Letras e Comunicação (ILC), atuando na Faculdade de Letras Estrangeiras Modernas (FALEM) da Universidade Federal do Pará (UFPA). Doutor (2015) em Literatura pela Universidade Federal de Santa Catarina (UFSC). É líder do grupo de pesquisa NELAA - Núcleo de Estudos em Literaturas e Artes Anglófonas. Atua nas áreas de Teoria Literária, Literatura de Língua Inglesa, Estética e Filosofia da arte, Poesia, Literatura Digital e Literaturas Experimentais.

Como citar esse artigo de acordo com as normas da revista

TAVARES, Otávio Guimarães. Anne Carson tradutora de Antígona: performance e tradução de um grito. Anuário de Literatura, Florianópolis, v. 25, n. 2, p. 119-138, 2020.

\section{Contribuição de autoria}

Não se aplica.

\section{Financiamento}

Não se aplica

\section{Consentimento de uso de imagem}

Não se aplica.

Aprovação de comitê de ética em pesquisa

Não se aplica.

\section{Licença de uso}

Este artigo está licenciado sob a Licença Creative Commons CC-BY. Com essa licença você pode compartilhar, adaptar, criar para qualquer fim, desde que atribua a autoria da obra.

\section{Histórico}

Recebido em: 31/05/2020

Aprovado em: 07/08/2020

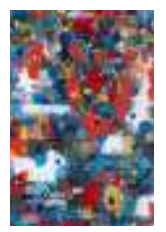

